\title{
Karakteristik Yakuwarigo dalam Tokoh Anime Gintama
}

\author{
Izzatul Maulina ${ }^{\mathrm{a}}$, Lisda Nurjaleka ${ }^{\mathrm{b}}$ \\ a Universitas Negeri Semarang, Semarang, 50229, Indones ia \\ $\mathrm{b}_{\text {Universitas Negeri Semarang, Semarang, 50229, Indonesia }}$ \\ *Corresponding Author. Tel +628979333781 \\ Email: lisda_nurjaleka@mail.unnes.ac.id
}

\begin{abstract}
Abstrak
Penelitian ini bertujuan untuk menganalisis dan mengkategorikan jenis yakuwarigo atau bahasa peran pada Anime Gintama. Bahasa peran, atau dikenal sebagai Yakuwarigo dalam bahasa Jepang, adalah serangkaian fitur bahasa yang terkait dengan jenis karakter tertentu di dunia virtual. Ciri khas variasi bahasa ini seperti kosa kata, tata bahasa, intonasi, dan pola aksen. (Kinsui, 2003). Penelitian ini juga menyelidiki fungsi dari jenis variasi bahasa ini yang berfokus pada jenis yakuwarigo di Anime Gintama. Teknik pengumpulan data yang digunakan adalah teknik note. Teknik analisis data yang digunakan dalam penelitian ini adalah teknik analisis markah membaca diikuti dengan teknik analisis data deskriptif kualitatif untuk mempresentasikan hasil analisis data. Hasil penelitian menunjukkan bahwa jenis Yakuwarigo yang ditemukan di Anime Gintama menunjukkan variasi karakter itu sendiri. Tujuh jenis yakuwarigo dilihat dari 10 karakter anime Gintama, yaitu, aruyo kotoba, hakase go, onee kotoba, joseigo, danseigo, chara gobi, dan Osaka ben. Dan tipe khusus dari karakteristik yakuwarigo adalah shujoshi dan tipe ekspresi tertentu yang digunakan oleh karakter ini.
\end{abstract}

\section{Kata kunci: Yakuwarigo; Anime; Gintama; Bahasa peran; Karakter}

\begin{abstract}
This study aims to analyze and categorize the type of yakuwarigo or role language on the Anime of Gintama. Role language, or known as Yakuwarigo in Japanese, is a set of language features associated with a particular type of character in the virtual world. The characteristic of these languages' variation such as vocabulary, grammar, intonation, and accent patterns. (Kinsui, 2003). This study also investigates the function of these language variation types focusing on the yakuwarigo types in Anime Gintama. The data collection technique that was used is the note technique. The data analysis technique used in this study was the reading markah analysis technique followed by a descriptive qualitative data analysis technique to present the results of the data analysis. The results show that the type of Yakuwarigo found in Anime Gintama shows the variation of the character itself. Seven types of yakuwarigo seen from 10 Gintama anime characters, namely, aruyo kotoba, hakase go, onee kotoba, joseigo, danseigo, chara gobi, and Osaka ben. And the particular type of the yakuwarigo's characteristics was shujoshi and specific types of expression used by these characters.
\end{abstract}

Keywords:Yakuwarigo; Anime; Gintama; Role language; Characters 


\section{Pendahuluan}

Idiolek adalah variasi bahasa yang bersifat perseorangan yang berbeda dengan orang lain sehingga menjadi ciri khas orang tersebut dalam berbicara. Menurut konsep idiolek, setiap orang mempunyai variasi bahasanya atau idioleknya masing-masing. Variasi idiolek ini berkenaan dengan "warna" suara, pilihan kata, gaya bahasa, susunan kalimat, dan sebagainya (Chaer dan Agustina, 2004). Contoh dari idiolek adalah yakuwarigo.

Yakuwarigo merupakan suatu susunan ungkapan atau cara bicara khusus yang berakar dari stereotip yang mencakup kosa kata, tata bahasa, ungkapan, intonasi, yang berkaitan dengan gambaran karakteristik seseorang seperti usia, pekerjaan, status sosial, zaman, penampilan wajah dan fisik, sifat dan sebagainya (Kinsui, 2011:34). Penggunaan yakuwarigo berfungsi untuk mendukung dan menguatkan karakter tokoh serta memberikan kesan sehingga tokoh mudah dikenali dan dibedakan antar tokoh lain berdasarkan perannya dalam cerita.

Kalimat-kalimat di bawah ini merupakan contoh jenis yakuwarigo yang diklasifikasikan menurut Kinsui (2003). Ke-lima kalimat berikut, jika diterjemahkan dalam bahasa Indonesia bermakna "ya, aku tahu":

\section{(a) Bahasa Profesor}

$$
\text { おお、そうじや、わしがしっ }
$$

ておるんじや。

Oo, souja, washi ga shittorunja.

\section{(b) Bahasa Tuan Putri}

あら、そうよ、わたくしが知って おりますわ。

Ara, souyo, watakushi ga shiiteorimasuwa.

(c) Bahasa Anak laki-laki

うん、そうだよ、僕がしって

るよ。

Un, soudayo, boku ga shitteruyo.

(d) Orang Kansai

そやそや、わしが知ってまっせ一。 Soyasoya, washi ga shittemassē.

\section{(e) Bahasa Samurai}

$$
\begin{aligned}
& \text { うむ、さよう、せっしゃが存じ } \\
& \text { ております。 } \\
& \text { Umu, sayou, sessha } g a
\end{aligned}
$$
zonjiteorimasu

(Kinsui, 2003)

Yakuwarigo merupakan ragam bahasa Jepang yang hanya digunakan dalam dunia virtual, berfungsi untuk memberikan karakteristik pada tokohtokoh dalam cerita dan berbeda dengan ragam bahasa Jepang yang digunakan dalam kehidupan sehari-hari. Kenyataannya, bahkan beberapa yakuwarigo tidak ada dan tidak digunakan dalam kehidupan nyata, 
misalnya aruyo kotoba. Pembelajar bahasa Jepang mempelajari bahasa Jepang diantaranya dengan menonton anime, membaca manga dan novel atau bermain game. Ragam bahasa Jepang yang digunakan didalamnya tentunya berbed a dari ragam bahasa Jepang yang dipelajari biasanya. Penelitian ini dapat digunakan untuk memperkenalkan pada pembelajar bahasa Jepang tentang ragam bahasa dunia virtual agar dapat memahami perbedaan ragam bahasa Jepang virtual dengan ragam bahasa Jepang yang dipelajari.

Rahardjo (2016), dalam artikel yang berjudul "Penggunaan Yakuwarigo (Role Language) Bahasa Jepang dalam Dialog Manga", menjelaskan bahwa yakuwarigo adalah ragam bahasa dalam dunia virtual yang merupakan karaktersitik dan identitas dari tokoh tersebut. Beberapa stereotip yang ditemukan dalam manga adalah bentuk yakuwarigo aruyo kotoba, yakuwarigo danseigo dan joseigo, serta yakuwarigo charagobi. Chara gobi mengacu pada akhiran kata atau kalimat yang digunakan oleh suatu tokoh dalam anime ataupun manga yang menjadi ciri khas atau keunikan dari karakter tersebut.

Selain itu Afifah (2019) menganalisis penggunaan yakuwarigo dalam situs web pembelajaran online “Anime/Manga no Nihongo". Situs web ini merupakan situs web pembelajaran bahasa Jepang yang dibuat oleh The Japan Foundation ditujukan untuk pembelajar bahasa kedua, yaitu bahasa Jepang. Dari hasil penelitiannya ditemukan ketidaksesuaian antara "character expressions" yang diperkenalkan dengan karakter yang muncul dalam manga dalam "expressions by scene". Ungkapanungkapan pada bagian perkenalan dengan ungkapan yang digunakan oleh karakter dalam manga ditemukan tidak sesuai.

Adapun Rahmawati (2015) menjelaskan dalam penelitiannya bahwa dialek Osaka yang ditemukan dalam buku cerita anak "Toire no kamisama" terd iri dari bentuk jodoushi, shuujoshi dan kosakata khusus berjumlah 21 buah. Adapun kalimat berpredikat verba yang banyak digunakan dalam buku cerita tersebut seperti bentuk VHen, Vna akan, $\sim$ Vharu, $\sim$ VTotte, $\sim$ Vte Morota, $\sim$ VTen, $\sim$ VTan serta bentuk kopula ya.

Andrássy (2014). melakukan penelitian yang berjudul "Vagabond: An Analysis of the Role Language in a Historical Japanese Comic". Penelitian ini bertujuan untuk mengetahui bagaimana cara tokoh manga Vagabond berbicara serta mengetahui ada tidaknya rangkaian ungkapan historis dan modern dalam dialog manga tersebut.

Penelitian kali ini membahas tentang jenis-jenis yakuwarigo yang ditemukan dalam tokoh anime Gintama. Gintama merupakan anime yang diadaptasi dari manga dengan judul yang sama karya Sorachi Hideaki. Plot utama Gintama menceritakan sudut pand ang kehid upan tokoh utama Sakata Gintoki bersama rekannya Shimura Shinpachi dan 
Kagura. Dalam penelitian ini, penulis memilih anime Gintama sebagai sumber data penelitian. Karena anime Gintama merupakan anime yang memiliki latar dan cerita yang terinsipirasi dari situasi dan keadaan Jepang ketika Zaman Edo. Selain itu, jumlah tokoh yang banyak serta memiiki latar belakang yang beraneka ragam, baik dari segi usia, status sosial, profesi, dan sebagainya membuat jenis yakuwarigo yang digunakan dalam tuturan yang ada pun bervariasi dan dapat menggambarkan dan/ mewakili yakuwarigo yang digunakan dalam contoh dunia virtual lainnya.

Tujuan penelitian ini adalah untuk menjawab rumusan masalah yaitu : 1) untuk mengetahui jenis yakuwarigo dalam anime Gintama, 2) untuk mengetahui fungsi dan penggunaan ungkapan dari jenis yakuwarigo yang ditemukan dalam anime tersebut. Melalui penelitian ini diharapkan agar pembaca dapat memperoleh informasi dan pengetahuan terkait ragam bahasa virtual terutama yakuwarigo yang digunakan dalam anime.

\section{Metode}

Penelitian ini menggunakan
metode deskriptif
Pualitatif.
Pendekatan deskriptif
dilakukan untuk menggambarkan atau
mendeskripsikan suatu fenomena yang
terjadi saat ini dengan menggunakan
prosedur ilmiah untuk menjawab
masalah secara aktual (Sutedi,2011:58).
Pada penelitian ini pendekatan tersebut
digunakan untuk mendeskripsikan

yakuwarigo yang terdapat dalam tuturan tokoh anime Gintama.

Data yang digunakan adalah kalimat ujaran tokoh karakter yang diambil dari dari sumber data anime Gintama. Karena jumlah episode dan tokoh dalam anime Gintama sangat banyak, maka penulis membatasi penelitian ini dengan hanya akan meneliti tuturan dari 10 tokoh anime Gintama. Teknik pengumpulan data yang digunakan yaitu teknik simak catat. Teknik analisis data yang digunakan dalam penelitian ini adalah teknik analisis baca markah dilanjutkan dengan teknik analisis data deskriptif kualitatif guna memaparkan hasil analisis data.

Langkah-langkah penelitian yang dilakukan dalam penelitian ini meliputi sebagai berikut:

1. Mencari takarir bahasa Jepang anime Gintama.

2. Melakukan reduksi data. Setelah takarir ditranskripsikan, penulis memilah tutran karena tidak semua tuturan akan dianalisis. Hanya tuturan yang terdapat yakuwarigo saja yang akan dianalisis.

3. Mengklasifikasi jenis yakuwarigo serta menyajikannya dalam bentuk tabel.

4. Menganalisis data

5. Mengemukakan hipotesis dari hasil analisis data. 


\section{Hasil dan Pembahasan}

Berikut ini akan dipaparkan hasil analisis dari penelitian ini. Ada 7 jenis yakuwarigo yang ditemukan pada tuturan 10 tokoh dalam anime Gintama, yaitu :

\subsection{Yakuwarigo Aruyo Kotoba}

Aruyo kotoba digunakan sebagai yakuwarigo tokoh karakter bernama Kagura. Tokoh Kagura digambarkan berpakaian tradisional Cina dan memiliki gaya rambut khas cepol dua. Dari tokoh Kagura, penulis menemukan 6 buah karakteristik yakuwarigo aruyo kotoba yang berupa 5 shuujoshi dan 1 tuturan.

\begin{tabular}{|l|c|}
\hline \multicolumn{2}{|c|}{ Karakteristik Aruyo Kotoba } \\
\hline Shuujoshi & aru,aruyo,aruna,arune,aruka \\
\hline Tuturan & yoroshi \\
\hline
\end{tabular}

Tabel 1. Karakteristik Yakuwarigo Aruyo Kotoba

Adapun contoh penggunaan yakuwarigo yang ditemukan dalam tuturan dari tokoh Kagura adalah sebagai berikut:

\section{Shuujoshi}

a. Kagura:「もう何もする気が

$$
\text { しないアル。」 }
$$

“Mou nanimo suruki ga shinai aru."

"Aku merasa tidak ingin melakukan apapun.”

(Episode 111 pada b. Kagura: 「プフッ! 頭ちゃんと

$$
\text { 使って生活してないからアル }
$$$$
\text { よ。」 }
$$

"Atama ga chanto tsukatte seikatsu shitenai kara aruyo."

" Ini karena kau tak menggunakan kepalamu dengan baik dalam kehidupan sehari-hari."

(Episode 73 pada 13:04-

Berdasarkan tuturan yang menggunakan aru dan aruyo sebagai shuujoshi di atas, fungsi dari aru dan aruyo dalam tuturan tersebut adalah untuk menekankan/menegaskan tuturan. Hal ini seperti apa yang dikemukakan oleh Kinsui bahwa shuujoshi aru dan aruyo dalam yakuwarigo aruyo kotoba berfungsi untuk menegaskan tuturan dan melekat setelah predikat akhir kalimat (Kinsui,2003:110).

Pada tuturan (a) fungsi aru untuk menekankan bahwa Kagura tidak ingin melakukan sesuatu, sedangkan tuturan (b) aruyo menekankan pendapat Kagura mengenai kejadian yang menimpa Gintoki.

Shuujoshi aru dan aruyo paling sering digunakan oleh tokoh Kagura dan menjadi ciri khas tokoh tersebut dalam berbicara.

\section{Tuturan}

a. Kagura:「おかわりよろ

$$
\text { ᄂᄂ?」 }
$$


Kiryoku, Volume 4 No 12020

e-ISSN: 2581-0960 p-ISSN: 2599-0497

Tersedia online di http://ejournal.undip.ac.id/index.php/kiryoku

(Episode 12 pada 05:23-

$05: 26)$

b. Kagura：「挨拶するよろし」

“Aisatsu suru yoroshi”"

"Beri salam"

(Episode 40 pada 14:28-14:30)

Menurut Kinsui, yoroshi dalam aruyo kotoba berfungsi untuk menyatakan perintah atau permintaan (Kinsui, 2003:110).

Yoroshi dalam tuturan (a) berfungsi sebagai penanda bentuk permintaan izin dan dapat dipadankan dengan bentuk permintaan seperti temo ii desuka. Sedangkan yoroshi yang ada pada tuturan (b), berfungsi sebagai penanda bentuk perintah dan dapat dipadankan dengan bentuk perintah seperti nasai dan bentuk perintah $\sim$ te kudasai.

\subsection{Bahasa Profesor (Hakase go)}

Yakuwarigo hakase go memiliki karakteristik khas seperti penggunaan washi sebagai pronomina pertama, ja sebagai kopula dan pengganti $d a$, serta akhiran nou dan wai yang digunakan sebagai partikel akhir tuturan (Kinsui, 2003: 4). Yakuwarigo ini digunakan oleh tokoh bernama Okuni.

Ada 10 karakteristik yakuwarigo hakase go yang penulis temukan pada tuturan yang tokoh Okuni ujarkan, terdiri dari 1 pronomina, 6 shuujoshi, dan 3 tuturan.

\begin{tabular}{|l|l|}
\hline \multicolumn{2}{|c|}{ Karakteristik Karakteristik Hakase go } \\
\hline Pronomina & Washi \\
\hline Shuujoshi & ja,jazo,jaro, nou, kai,wa \\
\hline Tuturan & nu/n, teoru \\
\hline
\end{tabular}

Tabel 2.Karakteristik Yakuwarigo Bahasa Professor

Adapun contoh penggunaan yakuwarigo yang ditemukan dalam tuturan dari tokoh Okuni ad alah sebagai berikut:

\section{Pronomina}

Okuni：「ワシはなかなか外に出

してもらえんから買いに行け

んのじゃ。」

"Washi wa nakanaka soto ni dashite moraen kara kai ni iken no ja."

" Aku tidak diperbolehkan keluar jadi tidak bisa membelinya."

(Episode 63 pada 08:09-

08:11)

Tokoh Okuni menggunakan washi untuk menyebut dirinya sendiri terlepas dari pengaruh situasi atau lawan bicara. Pada tuturan di atas, diucapkan dalam situasi santai dengan lawan bicara yang merupakan pria dewasa.

\section{Shuujoshi}

Okuni: 「構わん。ちょうど今 週号が読みたかったところじ p。」

"Kamawan. Choudo konshuugou ga 
yomitakatta tokoro $\underline{j a}$ ”. " Tidak perlu. Kebetulan aku ingin membaca edisi minggu ini."

(Episode 63 pada 03:55-03:58)

Berdasarkan contoh tuturan diatas, shuujoshi ja berfungsi sebagai penegas dalam tuturan menggantikan $d a$. Hal ini sesuai dengan apa yang dikatakan oleh Kinsui bahwa di dalam hakase go, shuujoshi ja digunakan sebagai pengganti $d a$ dalam tuturan untuk menyatakan penegasan (Kinsui, 2003:4). Ketika mengetahui bahwa barang yang ia antarkan adalah pizza, Zenzo meminta maaf dan ketika ia berniat untuk mengganti, Okuni menegaskan bahwa hal tersebut tidak perlu untuk dilakukan.

\section{Tuturan}

Okuni：「どこへでも連れてい くがよい。覚悟はできておる。」 “Dokodemo tsureteiku ga yoi. Kakugo wa deki teoru."

"Bawa saja kemanapun kau suka. Aku sudah siap."

(Episode 63 pada 18:07-18:11)

Di dalam hakase go, tuturan teoru digunakan untuk menunjukkan suatu keadaan/ kondisi yang berkelanjutan/progresif (Kinsui, 2003:4). Pola teoru dapat dipadankan dengan tuturan $\sim$ teiru pada bahasa Jepang standar. Dekiteoru dalam tuturan di atas jika dipadankan dengan bahasa Jepang standar maka menjadi dekiteiru.

\subsection{Onee Kotoba}

Abe dalam Kawano (2016: 115) menyatakan bahwa onee kotoba adalah tindak tutur yang dengan terampil memanfaatkan bahasa yang memiliki karakteristik stereotip feminin dan maskulin.

Penulis menemukan Ada 9 karakteristik onee kotoba yang digunakan oleh tokoh onee kyara bernama Saigou Takumori, terdiri dari 3 kata dari kategori pronomina 5 shuujoshi dan 1 tuturan.

\begin{tabular}{|l|l|}
\hline \multicolumn{2}{|c|}{ Karakteristik Onee Kotoba } \\
\hline Pronomina & atashi,anta,teme \\
\hline Shuujoshi & wa,wayo,na,sa \\
\hline Tuturan & na,dai \\
\hline Tabel 3. Karakteristik Onee Kotoba \\
\multicolumn{2}{|c|}{ Adapun contoh penggunaan } \\
yakuwarigo yang ditemukan dalam \\
tuturan dari dari tokoh Saigou \\
Takumori adalah sebagai berikut:
\end{tabular}

\section{Pronomina}

Saigou:「伂ね お客さんこんな ことで山キにならないでよ。ほら

ア多のあげるから」 
" Iyane okyakusan, konna koto de muki ni naranai deyo. Hora atashi no ageru kara."

" Tenang dulu tuan, jangan marah karena hal sepele ini. Ini, aku berikan punyaku."

(Episode 24 pada 04:32-

Atashi merupakan kata ganti orang pertama seperti halnya watashi. Namun berbeda dengan watashi yang dapat digunakan baik oleh pria maupun wanita, atashi secara khusus digunakan oleh penutur wanita. Untuk menunjukkan kefeminitasnya, Onee kyara menggunakan ungkapan wanita seperti atashi dan kemudian otomatis menyesuaikan kepribadian dan karakternya menjadi seperti seorang wanita. Namun pada kasus tokoh Saigou, berdasarkan pengamatan dari setiap tuturan yang diujarkan olehnya, penulis menemukan bahwa penggunaan pronomina pertama atashi pada tokoh tersebut tidak mempengaruhi perubahan karakternya. Baik ketika Saigou sedang menjalankan karakter sebagai seorang wanita atau pria ia tetap menggunakan atashi.

\section{Shuujoshi}

$$
\begin{aligned}
& \text { Saigou：「仸少だったけど人 } \\
& \text { が足りないときに来てもらっ } \\
& \text { て助かったわ。」 } \\
& \text { “Mechakucha datta } \\
& \text { kedo hito ga tarinai toki } \\
& \text { ni kite moratte tasukatta }
\end{aligned}
$$

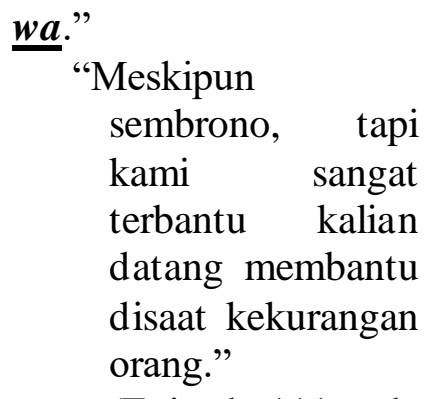

(Episode 111 pada

02:22-02:28)

Partikel Shuujoshi wa yang digunakan tokoh Saigou pada tuturannya masuk dalam ungkapan wanita karena pengucapan wa oleh tokoh Saigou yang menggunakan intonasi nada naik (Kinsui,2003:83). Shuujoshi wa sendiri selain berfungsi untuk menegaskan kalimat juga untuk mengekspresikan perasaan pembicara. Untuk situasi ketika tuturan di atas diujarkan, Saigou menggunakan partikel Shuujoshi wa untuk mengekspresikan perasaan terima kasihnya kepada Gintoki, Shinpachi dan Kagura karena telah membantunya. Selain menggunakan partikel Shuujoshi $w a$, Saigou juga berbicara dengan cara yang lebih sopan dan intonasi lebih lembut dari biasanya.

\section{Tuturan}

$$
\begin{aligned}
& \text { Saigou：「あの子を傷つけたりし } \\
& \text { たらどうするんだい?」 } \\
& \text { “Ano ko wo kizutsuketari } \\
& \text { shitara dou surun dai??” } \\
& \text { "Bagaimana kalau ia } \\
& \text { terluka?” } \\
& \text { (Episode } 111 \text { pada 09:35- }
\end{aligned}
$$


Akhiran $\sim$ dai digunakan sebagai penanda tanda tanya seperti halnya desuka atau partikel tanya $k a$ namun bedanya, penanda tanda tanya dai masuk ke dalam ungkapan pria dan secara khusus digunakan oleh penutur pria (Kinsui, 2003:82). Tokoh Saigou menggunakan partikel tanya $\sim d a i$ ketika dalam situasi serius dan iapun mengubah kepribadiannya menjadi seorang pria yang berbicara menggunakan gaya maskulin.

\subsection{Joseigo}

Tokoh dalam anime Gintama yang menggunakan yakuwarigo jenis ini sebagai ciri khas ia berbicara adalah Shimura Otae. Ungkapan wanita digunakan sebagai yakuwarigo tokoh Otae dengan tujuan untuk lebih mendukung penggambaran karakter tokoh. Tokoh Otae digambarkan sebagai wanita yang berpenampilan dan berperilaku elegan, feminin serta penuh perhatian.

Penulis menemukan ada 8 karakteristik khas yakuwarigo joseigo yang digunakan oleh tokoh Otae, terdiri dari 7 buah shuujoshi dan 1 buah tuturan.

\begin{tabular}{|l|l|}
\hline \multicolumn{2}{|c|}{ Karakteristik Joseigo } \\
\hline Shuujoshi & $\begin{array}{l}\text { wa,noyo, dawa,wayo,no,wa } \\
\text { ne, koto }\end{array}$ \\
\hline Tuturan & kashira \\
\hline
\end{tabular}

Tabel 4. Karakteristik Yakuwarigo Joseigo
Adapun contoh penggunaan yakuwarigo yang ditemukan dalam tuturan dari tokoh Otae adalah sebagai berikut :

\section{Shuujoshi}

$$
\begin{gathered}
\text { Otae :「あら ホ小奇遇ですこと」 } \\
\text { “Ara honto kiguu desu } \\
\text { koto." } \\
\text { "Ah, memang, benar-benar } \\
\text { kebetulan.” } \\
\quad \text { (Episode } 28 \text { pada 22:30- }
\end{gathered}
$$

Meskipun shuujoshi koto masuk ke dalam ungkapan wanita, menurut Kinsui, shuujoshi $\sim$ koto lebih khusus merupakan salah satu karakteristik yakuwarigo ohime sama kotoba (bahasa tuan putri) dan digunakan di akhir tuturan untuk mengeskspresikan kekaguman (Kinsui, 2003:80). Sesuai dengan namanya, yakuwarigo ohime sama kotoba merupakan yakuwarigo yang digunakan oleh karakter tuan putri. Karakter tuan putri adalah karakter yang dideskripsikan sebagai wanita/putri bangsawan yang tinggal dalam istana dan bertingkah seperti seorang ratu. Berbed a dengan deskripsi tokoh pada karakter tuan putri, tokoh Otae hanyalah seorang wanita biasa pemilik dojo yang ditinggalkan oleh ayahnya.

Selain itu, jika dilihat berdasarkan situasi tuturan tersebut diujarkan, koto digunakan bukan untuk menunjukkan perasaan kekaguman melainkan adanya perasaan tidak senang yang diarahkan 
Kiryoku, Volume 4 No 12020

e-ISSN: 2581-0960 p-ISSN: 2599-0497

Tersedia online di http://ejournal.undip.ac.id/index.php/kiryoku

Otae pada Kondo. Dengan demikian, dapat dikatakan bahwa fungsi shuujoshi koto dalam kalimat di atas tidak sesuai dengan fungsi menurut Kinsui yang mengatakan bahwa shuujoshi koto digunakan untuk menyatakan ekspresi kekaguman.

\section{Tuturan}

$$
\begin{aligned}
& \text { Otae：「今日も お休みしてたわ } \\
& \text { ね。どうしたのかしら?」 } \\
& \text { “Kyou mo oyasumi shiteta } \\
& \text { wane. Doushita no } \\
& \text { kashira? ?” "Hari ini juga ia tidak } \\
& \text { berangkat, kenapa ya?" }
\end{aligned}
$$

(Episode 36 pada 00:43-

Tuturan kashira termasuk dalam ungkapan wanita dan pemakaian tuturan di atas digunakan untuk menyatakan tuturan tanya.

\subsection{Danseigo}

Anime Gintama merupakan anime yang berlatar pada zaman Edo. Karena itu, tokoh-tokoh yang ada didalamnya, mayoritas merupakan laki-laki agar dapat menggambarkan kehidupan para samurai dan nuansa politik di kala itu.

Penulis menemukan ada 9 karakteristik ragam bahasa pria yang digunakan oleh Gintoki, Shinpachi, Matsudaira, dan Hijikata. Kesembilan karakteristik tersebut terdiri dari 2 pronomina, 1 tuturan dan 6 shuujoshi.

\begin{tabular}{|l|l|}
\hline \multicolumn{2}{|c|}{ Karakteristik Danseigo } \\
\hline Pronomina 1 & ore, boku \\
\hline Shuujoshi & sa,ze,zo, dayo, wa,kai \\
\hline Tuturan & tamae \\
\hline
\end{tabular}

Tabel 1. Karakteristik Yakuwarigo Danseigo

Adapun contoh penggunaan yakuwarigo yang ditemukan dalam tuturan adalah sebagai berikut:

\section{Pronomina}

$$
\begin{aligned}
& \text { Shinpachi： 「アンタを殺して } \\
& \text { も死ぬ!!」 } \\
& \text { “Anta wo koroshite } \\
& \text { boku mo shinu!!” } \\
& \text { "Akan kubunuh kau } \\
& \text { setelah itu aku akan } \\
& \text { bunuh diri” }
\end{aligned}
$$

Menurut Kinsui, kata ganti boku digunakan untuk mengasosiasikan karakter yang penurut dan lemah yang harus selalu dilindungi. Boku memberikan kesan lemah pada penuturnya (Kinsui,2003:77). Diantara keempat tokoh, Shinpachi merupakan tokoh yang paling muda. Ia tidak memiliki pengalaman di medan perang, dan kemampuan bertarungnya juga dibawah lainnya. Ia digambarkan sebagai anak penurut dan selalu menjadi penengah jika Gintoki atau Kagura membuat masalah. Jika dalam situasi berbahaya, Gintoki atau Kagura selalu ada untuk melindunginya. 


\section{Shuujoshi}

Gintoki:「そうすりやあア似も 新たな明日に向かう必要に気 づくさ。」

"Sou suryaa aitsu mo aratana ashita ni mukau hitsuyou kidzuku sa"

" Dan ketika hal itu terjadi, dia akhirnya sadar pentingnya hidup untuk menyambut esok hari "

(Episode 111 pada 10:09-10:14)

Partikel akhir tuturan sa menurut Kinsui, masuk dalam ragam Bahasa pria (Kinsui, 2003:83). Shuujoshi sa terletak setelah kata kerja kidzuku yang bermakna sadar. Dalam tuturan di atas, Gintoki ingin menekankan bahwa subjek pembicaraan akhirnya akan menyadari sesuatu jika hal itu terjadi padanya. Gintoki menggunakan shuujoshi sa untuk menegaskan/menekankan tuturan yang diucapkan olehnya dengan tanpa memberikan kesan kasar seperti yang terd apat pada bentuk bentuk penegasan lain seperti $d a$ atau yo.

\section{Tuturan}

Gintoki：「いやいや安心したま 元新八君。」

"Iya iya anshin shitamae Shinpachi kun"

" Tenanglah Shinpachi kun."

(Episode 11 pada 02:36-

Tamae dulunya digunakan oleh Samurai pada periode Edo dan termasuk dalam bahasa yang digunakan oleh kalangan anak muda Jepang kala itu. Namun di era modern seperti sekarang, tamae digunakan sebagai salah satu yakuwarigo tokoh seorang bos pria senior yang memiliki kedudukan atau kekuasaan tertentu dalam tatanan sosial melebihi bawahannya (Kinsui, 2003: 66). Gintoki merupakan pendiri Yorozuya, hal ini otomatis menjadikannya sebagai bos, sedang Kagura dan Shinpachi adalah rekan kerja atau bawahannya. Tamae pada tuturan di atas berfungsi sebagai perintah dari Gintoki untuk Shinpachi agar ia tetap tenang dan tidak tersulut emosi oleh Kagura. Selain Gintoki, Hijikata dan Matsudaira juga sering menggunakan tuturan tersebut. Hal ini dikarenakan profesi Hijikata dan Matsudaira yang bekerja sebagai aparat keamanan yang memiliki status sosial tinggi melebihi para bawahannya.

\subsection{Chara Gobi}

Dalam anime Gintama, chara gobi ditemukan pada tokoh bernama Matsudaira Kuriko. Chara gobi mengacu pada perubahan pada akhiran kata maupun kalimat. Fungsi utama chara gobi adalah untuk menandai dan memberi karakteristik khas pada suatu tokoh dibandingkan tokoh lainnya yang ada dalam cerita. Kuriko memiliki cara 
bicara khas yang berbeda dari tokoh lainnya. Ketika ia berbicara, ia menambahkan akhiran ru pada tuturan yang ia ujarkan.

Penulis menemukan satu karakteristik yakuwarigo chara gobi pada tokoh Kuriko. Karakteristik tersebut berupa akhiran kata/tuturan $r u$.

\begin{tabular}{|l|l|}
\hline \multicolumn{2}{|c|}{ Karakteristik Chara Gobi } \\
\hline Shuujoshi & $r u$ \\
\hline
\end{tabular}

Tabel 6. Karakteristik Chara Gobi

Adapun contoh penggunaan yakuwarigo yang ditemukan dalam tuturan tokoh Kuriko adalah sebagai berikut:

Kuriko：「あなた様が好きなもの は私も好きになりたいでございま する。」

"Anata sama ga sukina mono wa watashi mo suki ni naritai de gozaimasuru"

“ Apa yang kau suka, aku juga menyukainya"

(Episode 114 pada 14:55-15:00)

Chara gobi ru tokoh Kuriko hanya berfungsi sebagai shuujoshi. Ru dalam tuturan di atas, ditambahkan setelah kata gozaimasu yang kemudian menjadi gozaimasuru. Penulis menemukan bahwa akhiran ru hanya ditambahkan pada akhir tuturan dalam bentuk masu.

\subsection{Osaka Ben (Dialek Osaka)}

Dalam anime Gintama, tokoh karakter yang menggunakan dialek Osaka sebagai yakuwarigo adalah Hanako. Hanako merupakan seorang pendatang dari Osaka. Ia berbicara menggunakan dialek Osaka dan digambarkan memiliki karakteristik kepribadian orang Osaka berdasarkan stereotip yang menempel pada orang Osaka. Hanako dikarakteristikkan sebagai seorang pemberani, ceria,dan banyak bicara.

Penulis menemukan ada 10 karakteristik khas yakuwarigo dialek Osaka terdiri dari 3 shuujoshi, 2 kalimat berpredikat verba, 1 kopula, dan 4 tuturan.

Tabel 7. Karakteristik yakuwarigo dialek Osaka

\begin{tabular}{|l|l|}
\hline \multicolumn{2}{|c|}{ Karakteristik Osaka ben } \\
\hline Shuujoshi & nen, de,wa \\
\hline $\begin{array}{l}\text { Kalimat } \\
\text { berpredikat } \\
\text { verba }\end{array}$ & Vhen, Vhen \\
\hline Kopula & ya \\
\hline Tuturan & $\begin{array}{l}\text { akan, honma,yanoni, } \\
\text { shanai }\end{array}$ \\
\hline
\end{tabular}

Tabel 7. Karakteristik Osaka Ben

Adapun contoh penggunaan yakuwarigo yang ditemukan dalam tuturan tokoh Hanako adalah sebagai berikut: 


\section{Shuujoshi}

$$
\begin{aligned}
& \text { Hanako：「けど... 江戸はみんな } \\
& \text { 冷たいねん」 } \\
& \text { “Kedo.. Edo wa minna } \\
& \text { tsumetai nen” } \\
& \text { “ Tapi.. semua orang } \\
& \text { di Edo begitu dingin.” } \\
& \text { (Episode } 36 \text { pada 08:59- }
\end{aligned}
$$

Shuujoshi nen dalam dialek Osaka memiliki fungsi yang sama dengan partikel no/n (da) atau no/n (desu) dalam bahasa Jepang standar yang menunjukkan pernyataan. Dalam tuturan di atas, Jika dilihat dari situasi ketika Hanako mengucapkan tuturan tersebut, tsumetainen jika diubah ke dalam bahasa Jepang standar akan menjadi tsumetaino da. Tuturan tersebut diucapkan dalam situasi nonformal dan pembicara dan lawan bicara merupakan rekan kerja dan memiliki hubungan yang dekat seperti saudara. Selain menunjukkan pernyataan, akhiran nen juga berfungsi untuk menunjukkan adanya perasaan kecewa yang dirasakan Hanako mengenai penduduk Edo. Hal ini ditandai dengan intonasi naik untuk menambahkan nuansa kekecewaan yang dirasakan Hanako.

\section{Kalimat Berprerdikat Verba}

$$
\begin{aligned}
\text { Hanako : } & \lceil\text { 騙されてん!」 } \\
& \text { “Damasareten!"” } \\
& \text { “Aku ditipu!” } \\
& \text { (Episode } 36 \text { pada 06:36- }
\end{aligned}
$$

Verba+ten dalam dialek Osaka berfungsi sebagai penanda bentuk lampau ta. Tuturan damasareten apabila diubah dalam bentuk bahasa Jepang standar maka akan menjadi damasareta.

\section{Kopula $Y a$}

$$
\begin{gathered}
\text { Hanako：「大阪は人情の街や」 } \\
\text { “Osaka wa ninjou no } \\
\text { machi ya” } \\
\text { “ Osaka adalah kota } \\
\text { yang ramah" }
\end{gathered}
$$

(Episode 36 pada 08:51-08:53)

Kopula ya dalam dialek Osaka jika dipadankan dengan bahasa Jepang standar adalah kopula da/desu. Jika dilihat dari situasi ketika tuturan tersebut diucapkan, ya dalam tuturan di atas berfungsi untuk menunjukkan kalimat pernyataan.

\section{Tuturan}

$$
\begin{aligned}
& \text { Hanako：「あかん,ごめん...」 } \\
& \text { "Akan, gomen" } \\
& \text { "Oh tidak, maaf" } \\
& \text { (Episode } 36 \text { pada 05:30- }
\end{aligned}
$$
(larangan).

\section{Simpulan}

Melalui penelitian yang telah dilakukan, dapat disimpulkan bahwa, yakuwarigo merupakan ragam bahasa 
Jepang yang hanya digunakan dalam dunia virtual seperti anime, manga dan game yang berfungsi untuk menunjukkan ciri khas tokoh dalam suatu cerita. Latar belakang tokoh dapat dilihat melalui jenis yakuwarigo yang digunakan oleh tokoh dan hal ini erat kaitannya dengan kepribadian dari tokoh tersebut.

Dari hasil menganalisis tuturan 10 tokoh dalam anime Gintama, penulis menemukan ada 7 jenis yakuwarigo yang digunakan yaitu aruyo kotoba, hakase go, onee kotoba, joseigo, danseigo, chara gobi, dan Osaka ben. Dari ketujuh jenis yakuwarigo tersebut, diketahui bahwa yakuwarigo yang ditemukan banyak diantaranya berfungsi sebagai shuujoshi, dan tuturan.

\section{Referensi}

Afifah, M. (2019). Yakuwarigo dalam Situs web Pembelajaran Online "Anime /Manga no Nihongo". Chi'e: Journal of Japanese Learning and Teaching, 7(1), 2229.

Andrássy, H. (2014). Vagabond. An analysis of the role language in a historical Japanese comic.

Chaer, Abdul., dan Leonie Agustina. (2004). Sosiolinguistik Perkenalan Awal. Jakarta: PT RINEKA CIPTA.

Kawano, Ayami. (2016). Onee Kyarakuta no Ninshou:Variety Bangumi to Fiction Sakuhin no
Zairyou ni. Hikaku Nihongo Kyouiku Kenkyu Senta- Kenkyuu nenpou Dai12gou, Ochanomizu Joshi daigaku daigakuin, 115-122. Kinsui, S. (2003). Virtual Nihongo Yakuwarigo no Nazo. Tokyo : Iwanami Shoten.

(2011). Role Language and Teaching Japanese as a Foreign Language. Nihongo Kyouiku 150 (0). Nihongo kyouiku Gakkai, 3441.

Kesuma, T. M. J. (2007). Pengantar Metode Penelitan Bahasa.Yogyakarta: Carasvati Books

Rahardjo, Hardianto. (2016).

Penggunaan Yakuwarigo (Role Language) Bahasa Jepang dalam Dialog Manga. Jurnal Pendidikan Bahasa Jepang ASPBJI Korwil Jabar, Vol.10 No.2, 100-108. https://repository.widyatama.ac.id/ xmlui/bitstream/handle/12345678 $9 / 8$

811/Full\%20Paper\%20Hardianto $\%$ 20Rahardjo.pdf?sequence $=1$

Rahmawati, Hanum dan Bayu Aryanto. (2015). Analisis Padanan Dialek Osaka ke Bahasa Jepang Standar dalam Buku Cerita Anak Toire no Kamisama. Unpublished Thesis of Universitas Dian Nuswantoro.

Sudjianto dan Ahmad Dahidi. (2007).

Pengantar Linguistik Bahasa Jepang. Jakarta: Kesaint Blanc Sutedi, Dedi. (2011). Penelitian Pendidikan Bahasa Jepang. Bandung: UPI Press dengan Humaniora 